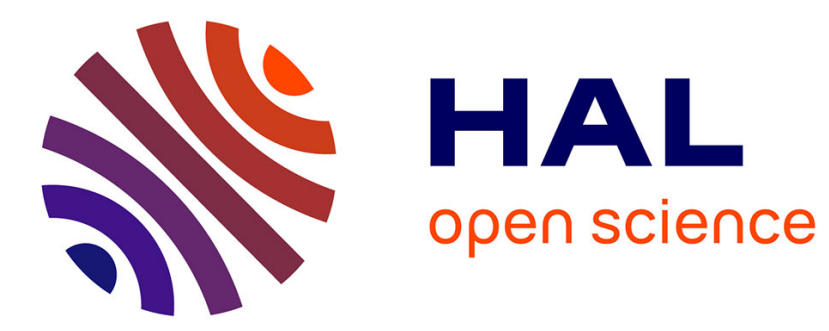

\title{
Localized Responses to Unsustainable Growth
}

Hélène Ducros

\section{To cite this version:}

Hélène Ducros. Localized Responses to Unsustainable Growth. Global Environmental Politics, 2014, 14 (2), pp.122-128. 10.1162/GLEP_a_00232. hal-03565173

\section{HAL Id: hal-03565173 \\ https://hal.science/hal-03565173}

Submitted on 10 Feb 2022

HAL is a multi-disciplinary open access archive for the deposit and dissemination of scientific research documents, whether they are published or not. The documents may come from teaching and research institutions in France or abroad, or from public or private research centers.
L'archive ouverte pluridisciplinaire HAL, est destinée au dépôt et à la diffusion de documents scientifiques de niveau recherche, publiés ou non, émanant des établissements d'enseignement et de recherche français ou étrangers, des laboratoires publics ou privés. 


\section{PROJECT MUSE}

Localized Responses to Unsustainable Growth

Hélène Ducros

nGlobal

Environmental

Politics

Global Environmental Politics, Volume 14, Number 2, May 2014, pp. 122-128 (Review)

Published by The MIT Press

$\Rightarrow$ For additional information about this article https://muse.jhu.edu/article/545871 


\title{
Book Review Essay
}

\section{Localized Responses to Unsustainable Growth}

\author{
Hélène Ducros
}

De Young, Raymond, and Thomas Princen, eds. 2012. The Localization Reader: Adapting to the Coming Downshift. Cambridge, MA: MIT Press.

Scruton, Roger, 2012. How to Think Seriously About the Planet: The Case for an Environmental Conservatism. Oxford University Press.

Rask, Mikko, Richard Worthington, and Minna Lammi, eds. 2012. Citizen Participation in Global Environmental Governance. Earthscan.

As another IPCC report about the causes and effects of climate change is under consideration by decision-makers everywhere, many question the scale of action best able to bolster resilience in the face of environmental crises and the always contested tragedy of the commons. How can individuals and societies live well under the constraints of a finite environment? This question points to the entanglement between local and global dynamics, endogenous and exogenous factors, and the intensification of multi-scale experiments in how to interpret and implement the slogan "think globally, act locally."

Three recent books attempt to provide responses in this debate. In The Localization Reader: Adapting to the Coming Downshift, editors Raymond De Young and Thomas Princen gather a collection of interdisciplinary historic and contemporary texts to advocate for the downscaling of human activities and the necessity of preparing for the consequences of downscaling through "positive localization." Also focused on the local, Robert Scruton, in How to Think Seriously About the Planet: The Case for an Environmental Conservatism, puts forward a conservative response to environmental problems, rooted in territorial attachment and homescape. Finally, in Citizen Participation in Global Environmental Governance, Mikko Rask, Richard Worthington, and Minna Lammi contribute detailed accounts of a specific case of place-based citizen mobilization with regard to influencing environmental global policy-making, the 2009 World Wide Views on Global Warming (WWViews). All three books ascertain the root of the environmental crisis, propose solutions, and address challenges that may arise. 
The Localization Reader contextualizes and reframes the changing relationship between humans and the finite planet they inhabit. It opens an interdisciplinary conversation about designing and transitioning to a resourceconstrained future based on "positive localization." Simply defined as "a process of social change pointing towards localities" (p. xvii), positive localization is centered on place specificity and the everyday. More important, the editors use the concept of localization to demonstrate that consumerism and commercialism cannot continue to grow in the face of finite resources, and to facilitate the necessary and already ongoing sustainable adaptation of institutions and individuals to the limits of natural systems. The edited volume not only relies on scholars from various disciplines, including sociology, political science, geography, biophysics, psychology, and landscape architecture, but also features writings by field analysts, practitioners and policy-makers, as well as environmental entrepreneurs and even farmers. All but three contributions have been adapted from previously published works. But far from being irrelevant, the assemblage of readings, covering over a century of scholarship on place-based sustainability, allows the reader to trace the intellectual trajectory of the philosophical movement, as well as become acquainted with contextualized experiments that have delved into the practical aspects of the localization transition over time. From the oldest (Josiah Royce's 1908 piece on the province as the appropriate scale for sustainability) to first publications on the practices of ecovillages throughout the world, the bounded system of fossil fuel dependence, and the final invitation to adopt the principles of localization that concludes the book, the volume establishes a compelling correspondence among numerous readings over time. It is a valuable addition to the literature, particularly suited to newcomers to the debate and practices of the localization project.

In How to Think Seriously about the Planet, Roger Scruton also rejects centralized large-scale and top-down projects as inadequate to solving contemporary environmental challenges. He invites environmentalists to consider conservatism as the perspective able to trigger environmental justice and individual intergenerational accountability. Backed by his interpretation of a remarkably rich and abundant set of historical, literary, artistic, and philosophical references, from Kant and Rawls to Stendhal and Rilke, Scruton centers his Burkean critique of the radical environmental movement around the concept of home and love of home, oikophilia. He uses this concept to further explore concepts in the sustainability debate, such as the role of culture and traditions in altruistic motivations; problems with utilitarian calculations of growth; technologydriven alienation, the place of the beautiful, the sacred, and the ways in which attachment to place is shaped by the law; and the issue of resilience and risk management. Although the book is intentionally ideological, it nevertheless uses a wide array of historical and geographic cases to illustrate the idea that environmental problems are problems of morality and psychology rather than economics. Scruton uses these cases to demonstrate that only local autonomy can lead to efficient territorial management, because it allows the valorization 
of practices based on care for one's home and one's nation. The book makes a thought-provoking contribution to the literature on place-based development, building from the British experience of place and national landscape aesthetics. In a strongly politically polarized global environmental policy context, the volume will compel customarily leftist environmentalists to address the author's critique and tighten their arguments, and thus will lead to advancement in the conversation over environmental challenges and solutions. While Scruton concludes that encouraging oikophilia constitutes the appropriate response to environmental challenges, he does not emphasize the concrete processes by which citizens are mobilized to put oikophilia into practice.

By contrast, in Citizen Participation in Global Environment Governance, editors Mikko Rask, Richard Worthington, and Minna Lammi invite the reader into the tangible world of deliberative democracy and the processes by which laypeople grounded in the local may gain relevance in climate change politics on a global scale. In evaluating the successes and shortcomings of the WWViews consultations that took place in 2009 in preparation for the Copenhagen UN Climate Change Conference, the volume's contributors also evaluate the potential for citizen participation in global environmental policy. Organized under the auspices of the Danish Board of Technology, 2009 WWViews was a pioneering global citizen deliberation project that gathered more than 4000 citizens across 38 countries from both the global North and South. Participants deliberated in groups about questions relating to climate change. To provide context, the book explains the history and methods of transnational deliberative democracy in complex societies, and offers a comparative analysis of other deliberative projects (all European-scale ventures). After presenting the general motivations, expectations, and procedures of the WWViews project, the contributing authors analyze what occurred during consultations in ten participating countries. They present an honest rendering of the accomplishments and disappointments encountered in project implementation at the local level, focusing on participant selection, content, policy impact, and media engagement. They also consider the effect of culture, language, gender, race, and class on the deliberative process, on capacity building and knowledge transfer, and on local assessment. The book frankly appraises the opportunities that validating ordinary people's views contributes to environmental governance. It informs the concept of global citizenship and the ways in which non-institutional constituencies and contextual particularities may intervene. It also seeks to study empirical data about democratic deliberation, claiming it is the first time this has been done.

The book can serve as a reference for future deliberative democracy projects; certainly, the analysis will help organizers of future WWViews and other transnational deliberative projects to address practical challenges. It might also allow global, national, or local environmental policymakers to glimpse what citizens in different places prioritize with respect to environmental stewardship and how they are affected locally by climate change policy. Interdisciplinary students in fields such as environmental studies, ecology, geography, or public 
policy interested in investigating multi-level approaches to environmental questions will find practical lessons on how to interconnect the local and the global in environmental governance.

These three volumes are all solution-driven. Each, in its own way, attributes value to the power, knowledge, and action of ordinary people on a localized scale in the face of the current environmental crisis, however the scale of reference is characterized. They differ in how they define and seek to implement localized action in response to global environmental challenges. Collectively, they cover a wide span of concepts and concrete case studies, but two themes recur in all three: first, the issue of growth and consumerism in the context of finite resources, limitless technology, and unbounded markets; and, second, the debate over the processes, scale of action, and actors most appropriate to support community resilience.

The issue of consumerism and modern societies' obsession with growth is addressed in all three books as a point of contention in the debate over community resilience and sustainability. The Localization Reader posits that current overconsumption and addiction to growth based on short-sighted individualism cannot be sustained. The contradiction between endless material growth and our finite planet should be approached as an ecological, social, personal, and political issue. Using various measures such as the peak oil principle, declining fossil fuel EROEI (energy returned on energy invested) and the Hubbert curve, the contributors prepare for the inevitability of the "downshift" and look for alternative futures where the relationship between humans and resources is reshaped. While advocating the transition to sustainable living through "degrowth" or "non-growth," several chapters emphasize that downshifting does not equate collapse or apocalypse for societies. It rather constitutes a redefinition of progress that recognizes that gigantism, and accelerating per capita rates of mass production and mass consumption, have become impossible to sustain. Markets fail ecologically because they are undemocratic, inequitable, based on faulty measures of energy system feasibility, and ignore psychological and behavioral factors, societal complexity and ingenuity, indirect extraction costs, supply and demand management costs, and environmental impact measures. "Market autism" or the "inattention to the social and biophysical contexts of behavior" (p. 243) leads to destruction because of the law of diminishing marginal returns on a planet with biophysical limits, where endless growth and infinite substitutability are just unviable. Raising the notion of "anticipated regret" (p. 4), the book suggests a "third way," defined as "applying and integrating the best practices of North and South with sensitivity to local context" (p. 137), or a "sustainability revolution," characterized as "organic," arising "from the visions, insights, experiments, and actions of billions of people," and able to "change the face of the land and the foundations of human identities, institutions, and cultures" (p. 313). The authors in this volume argue for a solution that favors simplicity over materialism, reduces scales of production, minimizes commodification, limits expansionism, and insists on progress "with a 
human face" based on renewable energy technology. Were the world to choose a different mental model going forward, material downshifting would spawn non-material upshifting. The "downshift moment," they argue, will create that new mental map: generating less material wealth, yet enhancing well-being.

Scruton is equivocal in his critique of growth. For him, the limits to growth controversy lies in the problematic measurement of GDP, which does not reflect environmental impact; for example, GDP may be boosted by environmental disasters (as the Localization Reader also points out). For this conservative scholar, the fundamental problem is that of failed solutions to the tragedy of the commons and incapacity to understand human motivations. Rather than seeing growth as addictive, he believes "the technological fix is addictive" (p. 246), and that utilitarian calculations are essentially inaccurate because future generations are unknown, as is their sense of responsibility. Scruton does not engage in the discussion over non-growth but of what he calls "steady-state economy." His position in the limitless growth debate is that a consensus exists about the need for growth to be sustainable, i.e. growth that can "go on for the foreseeable future without irreversible harm" (p. 382). His attitude is that he knows sustainable growth when he sees it: "I do not know whether a steadystate economy is achievable or desirable, but I can make good guesses as to what is or is not sustainable" (p. 382). He mainly targets unclean energy, but is critical of renewable energy schemes that may contribute to aesthetic pollution, such as wind turbines, privileging instead a vision of environmentalism grounded in cultural landscape "beauty" and aesthetic conventions as a basis for shared stewardship.

Like the Localization Reader's contributors, those of WWViews posit that the increased role of markets leads to their failure and that solutions lie in increased democracy. Their reflection on the relationship between consumerism and citizenship in climate change debates brings them to conclude that globalization enhances the power of nation-states and political mass mobilization opportunities, and that global markets redefine the interconnectedness of consumption and citizenship so that consumption becomes a political act that can impact climate change governance. As with both Scruton and "positive localizers," environmental deliberative democracy proponents avoid alarmist rants and engage in conversation over ways to foster resilience and promote alternative futures. Rather than a revolution, the reported recommendations made by WWViews participants for the necessary transition to sustainable consumption include reduced waste, vegetarianism, locally based production and consumption, product labelling, access to government information, local education and research initiatives, and more generally a mindful relationship between consumption and community. When it comes to markets, no consensus was observed and recommendations remained ambiguous, revealing an equity divide between industrialized and non-industrialized countries.

The second theme to which all three volumes speak concerns the processes, actors, and scale of action most conducive to community resilience. Both 
the Localization Reader and WWViews commentators rely on John Dryzek's discursive democracy thesis ${ }^{1}$ to look at ordinary people as repository of human ingenuity, and insist on the need for democratic decentralization for successful place-based solutions. Several Localization Reader contributors propose that communities and individuals be given a voice over that of experts and elites to answer environmental challenges. The appropriate scale of action they advocate is fundamentally local, defined by one contributor as physical and geographic proximity or the smallest jurisdiction with real tax authority. Practically, contributors have different interpretations of the local. But whether it refers to bioregion, village, province, or family farm, all are rooted in the experience of place. Some reminisce about Jeffersonian ideals and even feudalism. Yet, living in place and living with place do not mean that local civil society networks cannot have global reach. In fact, they can expand to large-scale movements through discourse and become "dynamic nodes of global engagement" (p. 129), while avoiding the harmful consequences of extreme localism, as the ecovillage project demonstrates. The instrument for the transition is "adaptive muddling" (p. 287), a process that is participatory, clean and honest, sensitive to local conditions and diversity, and provides a support structure to deal with challenges and mistakes. Adaptive muddling looks a lot like deliberative democracy.

Deliberative democracy also validates ordinary people's views and community-based research, emphasizes participation, prizes local competences and specializations, accounts for cultural variations, is honest in reporting limitations, and accounts for the "arena effect" (p. 211) and local civic epistemology context in deliberation. Additionally, it bridges the gap between citizens and scientific governance in supporting networks of small-scale exploration rather than large-scale implementation. Inspired by Dryzek's findings, WWViewers consider that democracy legitimizes decision-making when processes are public and information accessible. While the structural scale pertinent to WWViews is the nation-state, meticulous citizen selection seeks to account for even the most local standpoints, although the issue of representativeness proves a key challenge in the process.

Scruton also points to the failed record of large-scale projects when dealing with environmental issues. He agrees that the battle of experts is misleading as it is often motivated by political and other interests. For him, adaptation can only succeed at the local level because it depends on risk perception and risk management, which lie in culture, knowledge of place, and care for home. The crux of his conservative thesis is that "people ... find their social needs and aspirations in a familiar and loved environment, a place that is home to them and which they strive to improve" (p. 251). Oikophilia, the love of home, is "where all things are meaningful and irreplaceable" (p. 256). Humans appropriate the world through homescape, their Lebenswelt ("world of life," which they know through the way they interact with the world), and the act of dwelling. Scruton's 
agents of adaptation are Burke's "little platoons," embedded in "tradition," who act as volunteers, carrying with them local knowledge of what to do to counter failing NGOs and top-down governmental policies such as environmental treaties.

In the face of environmental challenges, the three books under review are about possibilities and experimental assessment. Together, they offer a historical account of the localization philosophy, practical examples of implemented local and transnational projects, and a terrain of reconciliation between different political approaches. They encourage scholars, decision-makers, and lay audiences to ponder the usefulness and adequacy of local action in environmental governance; the opportunities local stewardship offers to complex societies in designing alternative futures; and the limits that large-scale and small-scale local projects may suffer when dealing with environmental issues. In seeking solutions, they meet in considering the failure of markets and modern industrial values. Refraining from radical localism, they sensibly propose that local actors should have a voice in the battle of ideas and that actions rooted in local knowledge and care are best able to engender sustainability. In proposing ways to approach the necessary adaptation to the end of the era of limitless growth in the context of finite resources, they plead for a change of attitude and values away from exponential growth. However, practical lessons dictate that the consensus sought is often impinged by cultural constraints and different ways to apprehend the local. Thus, in pursuing solutions, the challenge is to make the conversation coherent. These books contribute to that effort.

\section{Reference}

Dryzek, John. 1990. Discursive Democracy: Politics, Policy and Political Science. Cambridge: Cambridge Press. 